\title{
Cinética mensual de parámetros químicos en la fase de prefloración en especies del género Nothofagus*
}

Resource allocation dynamics preceding flowering in species of the genus Nothofagus

\author{
M. RIVEROS ${ }^{1}$, M. PEREZ, P. BAEZ ${ }^{1}$, A. BAEZ ${ }^{2}$
}

${ }^{1}$ Instituto de Botánica, ${ }^{2}$ Instituto de Estadística, Universidad Austral de Chile, Campus Isla Teja, Casilla 567, Valdivia, Chile. E-mail: mrivero@uach.cl

\section{SUMMARY}

We studied the allocation of energetic compounds before flowering in four species of Nothofagus in South Central Chile to determine the individuals that were more likely to flower. Several individuals of N. obliqua, N. alpina, N. dombeyi and $N$. nitida were categorized according to the amount of starch, total soluble carbohydrates and total proteins stored in the medullar tissue (the pith) before flowering. Categories ranged from I (0 to 25\%) to IV (75\% to $100 \%)$. Most individuals that actually flowered previously accumulated a considerable amount of starch and fitted into categories III and IV. Deciduous species had a large accumulation of energetic compounds early in the year (categories III and IV), but before flowering resources decreased (categories I and II). The opposite was observed in evergreen species. Finally, total proteins slightly increased during autumn and winter, probably induced by the low temperatures during these periods.

Key words: Nothofagus, flowering, starch.

\section{RESUMEN}

Se analizaron los compuestos energéticos que presentan las especies del género Nothofagus durante el período previo a la floración, estableciendo a partir de dichos análisis cuáles son los individuos que florecerán. Para esto, se determinó en individuos de $N$. obliqua, $N$. alpina, $N$. dombeyi y $N$. nitida, previamente categorizados de acuerdo al contenido de almidón presente en el tejido medular, el contenido de carbohidratos solubles totales, proteínas totales y almidón. De los resultados obtenidos se puede concluir que la mayoría de los individuos del género Nothofagus que florecen acumulan gran cantidad de granos de almidón en el periodo previo a la floración, es decir, se ubican en categorías III y IV. Las especies caducifolias durante los primeros meses del año se mantuvieron en categorías III y IV para luego bajar a I y II en los meses previos a la floración. Un comportamiento totalmente opuesto presentaron las especies siempreverdes, presentando estos últimos mayor floración que los caducifolios. Las proteínas sólo mostraron un leve aumento en los meses de otoño e invierno, lo cual pudo deberse a la función protectora contra las bajas temperaturas en estos períodos.

Palabras claves: Nothofagus, almidón, floración.

\footnotetext{
* Proyecto financiado por DIDUACH $\mathrm{N}^{\circ} \mathrm{S}-98$ - 29 .
} 


\section{INTRODUCCION}

Los períodos reproductivos de floración y fructificación, junto con la emergencia y caída de las hojas, influyen en la fisonomía temporal de las comunidades de bosques. El estudio de los factores que determinan la secuencia temporal y duración de estas etapas se conoce como fenología (Borchet 1983).

Se ha señalado que en estudios fenológicos es importante considerar no sólo las condiciones fisiológicas, sino también las condiciones climáticas de los períodos de floración y fructificación, como también las ventajas y desventajas ecológicas y evolutivas de un determinado patrón de floración y fructificación (Gautier-Hion 1991).

Las especies del género Nothofagus, después del período invernal, inician el crecimiento vegetativo y reproductivo simultáneamente, es decir. desarrollan tallo, hoja y flor, lo que implica disponer de suficiente material energético para la formación de estas estructuras. Sin embargo, es sabido que las especies del género Nothofagus poseen una floración cíclica o periódica. Esto significa que hay individuos que en una temporada florecen y en la temporada siguiente no necesariamente lo hacen (Donoso 1987). Todos los aspectos relacionados con la floración constituyen un problema fisiológico complejo, regido por patrones, como la acumulación de almidón (Wardle 1984), hidratos de carbono, de los niveles de nitrógeno y de la actividad y nivel de hormonas de las plantas (Donoso 1993). Esto es particularmente importante en las especies de género Nothofagus, en las cuales se requerirían altos niveles de carbohidratos almacenados. En las caducifolias los carbohidratos se acumulan en el período previo a la caída de las hojas, es decir, a fines de verano-comienzo de otoño y en las siempreverdes se produce en el período previo a la floración. Todo esto permitiría mantener los gastos de crecimiento de la planta y el desarrollo de la flor (Bawa 1983).

En base a lo anteriormente expuesto se analizará el aporte de sustancias energéticas potencialmente inductoras del proceso de floración en cuatro especies del género Nothofagus: Nothofagus obliqua (Mirb.) Oerst., N. alpina (P. et E.), $N$. dombeyi (Mirb.) Oerst. y N. nitida (Phil.) Krasser, planteándose la siguiente hipótesis: los individuos del género Nothofagus que van a florecer, durante el período previo a la floración, deberían almace- nar mayores cantidades de carbohidratos, proteínas solubles y almidón para desarrollar estructuras tanto vegetativas como reproductivas, en relación a los individuos que no van a florecer.

Los objetivos de la investigación fueron establecer las cantidades de granos de almidón acumulados en la médula de leños de la última estación, en el período previo a la floración, con el objeto de poder categorizarlos, agrupándolos en diferentes categorías de acuerdo a dichas cantidades $\mathrm{y}$, finalmente, determinar en ramillas agrupadas por categorías los niveles de carbohidratos solubles totales, almidón y proteínas.

\section{MATERIAL Y METODOS}

Categorización de los individuos según acumulación de granos de almidón: Debido al diferente grado de acumulación que presentaron los individuos fue necesario crear categorías de acumulación de almidón. Mensualmente se realizaron, en promedio, cinco cortes transversales en varias ramillas de 1 año de edad en 23 individuos de $N$. obliqua, 27 de $N$. alpina, 10 de $N$. dombeyi y 8 de N. nitida. En los cortes se observó al microscopio óptico la presencia de granos de almidón en células parenquimáticas del tejido medular, previa tinción suave con lugol. Posterior a esto, los individuos fueron clasificados arbitrariamente de acuerdo al contenido de granos de almidón presentes en las células de la médula del tallo. Aquellos individuos cuyas ramillas se presentaban repletas de granos de almidón (entre 75 y 100\%) se agruparon en la categoría IV, las que presentaron entre 75 y $50 \%$ en como categoría III, las células de la médula que presentaron entre 50 y $25 \%$ se clasificaron en categoría II y, finalmente, las que poseían entre un 25 y $0 \%$ se agruparon en categoría I.

Determinación de carbohidratos solubles totales: Se llevó a cabo según Dubois et al. (1959). Dos gramos de peso fresco de tejido se homogeneizaron en un vértix con $10 \mathrm{ml}$ de agua caliente $\left(80^{\circ} \mathrm{C}\right)$. Posteriormente, el extracto se calentó a baño María a $60^{\circ} \mathrm{C}$ por 30 minutos y se centrifugó a 5.000 $\mathrm{r} / \mathrm{min}$ durante 30 minutos.

Esta operación se repitió tres veces. El residuo obtenido contiene almidón, lignina y otras sustancias, y el sobrenadante contiene azúcares y proteínas, entre otros. Se tomó $1 \mathrm{ml}$ del sobrenadante, 
se llevó a un tubo Eppendorf y se agregaron $10 \mu \mathrm{l}$ de ácido tricloroacético para precipitar las proteínas. Este conjunto permaneció a $4^{\circ} \mathrm{C}$ por 4 horas. Pasado este tiempo se tomó una alícuota de $20 \mu \mathrm{l}$, se agregaron $380 \mu \mathrm{l}$ de agua destilada, $10 \mu \mathrm{l}$ de fenol al $90 \%$ y $1 \mathrm{ml}$ de ácido sulfúrico concentrado. La digestión de la mezcla se llevó a baño María por una hora y se dejó enfriar. Una vez fría se midió la absorbancia a $485 \mathrm{~nm}$. La cuantificación se llevó a cabo comparando la absorbancia de la muestra con una curva estándar de glucosa. A partir de esta comparación se obtuvo la concentración de las muestras y a partir de dichas concentraciones se obtuvieron los microgramos por gramo de peso fresco de la muestra, expresados en equivalentes de glucosa.

Extracción y determinación de almidón: Se determinó a través de la metodología descrita por Dubois et al. (1959). En el residuo obtenido al extraer los carbohidratos solubles se determinó el almidón, previa hidrólisis con $13 \mathrm{ml}$ de ácido perclórico al $52 \%$ y $10 \mathrm{ml}$ de agua destilada. Esta solución se agitó por 20 minutos y luego se diluyó con $25 \mathrm{ml}$ de agua destilada. Posteriormente esto se centrifugó durante 30 minutos y se extrajo el sobrenadante. De la solución anteriormente preparada se tomó 1 $\mathrm{ml}$ y se llevó a un tubo Eppendorf, tomándose luego una alícuota de $30 \mu \mathrm{l}$, a la que se agregaron $370 \mu \mathrm{l}$ de agua destilada, $10 \mathrm{ml}$ de fenol al 95\% y $1 \mathrm{ml}$ de ácido sulfúrico concentrado. Esta mezcla se calentó a baño María a $100^{\circ} \mathrm{C}$ por una hora, dejándola enfriar. Una vez fría, se midió la absorbancia a $485 \mathrm{~nm}$. La cuantificación se realizó comparando la absorbancia de la muestra con una curva estándar de glucosa. A partir de esto se obtuvo la concentración de la muestra.

Determinación de proteínas totales: La extracción y cuantificación se realizó de acuerdo a Bradford (1976). Se tomaron 2 gramos de peso fresco de tejido y se trituraron en un homogeneizador con 10 $\mathrm{ml}$ de buffer fosfato $0,5 \mathrm{M}(\mathrm{pH} 7,0)$, y se centrifugó a $5.000 \mathrm{r} / \mathrm{min}$ durante 10 minutos. Del extracto se tomó una alícuota de $0,5 \mathrm{ml}$ y se diluyó en $0,5 \mathrm{ml}$ de agua destilada, para proceder a la cuantificación de las proteínas. Para ello se tomaron $0,2 \mathrm{ml}$ de la dilución y se mezclaron con $5 \mathrm{ml}$ de reactivo de Bradford (100 mg de azul brillante de Comasie G250 en $50 \mathrm{ml}$ de etanol $50 \%$ y $100 \mathrm{ml}$ de ácido ortofosfórico $85 \%$, aforando con agua destilada a un litro). La dilución obtenida anteriormente y mezclada con reactivo de Bradford se midió con espectrofotómetro a $595 \mathrm{~nm}$ y se comparó con una curva estándar de suero albúmina de bovino previamente preparado. A partir de esto se obtuvo la concentración, y posteriormente los microgramos por gramo de peso fresco de muestra.

Análisis estadísticos: Se utilizó un análisis de varianza con dos factores (meses e individuos de la misma especie) evaluando a través de las siguientes variables respuesta: concentración de almidón, concentración de carbohidratos solubles totales y concentración de proteínas. Posteriormente se procedió a realizar un test de comparaciones múltiples de Tukey, en el caso de que las variables resultaran significativas.

\section{RESULTADOS Y DISCUSION}

Categorías de los individuos durante el período de estudio: La acumulación de almidón en el parénquima medular presentó una amplia gama de situaciones durante el período de estudio y en los individuos observados (figuras 1 y 2). Se puede apreciar además que a través de los meses evaluados las especies caducifolias N. obliqua y N. alpina presentaron, en promedio, mayor contenido de almidón que las especies siempreverdes. Las caducifolias registraron tres momentos de mayor acumulación de almidón en los meses de marzo, junio y septiembre. Cabe destacar el elevado valor promedio que presentó la especie $N$. obliqua durante el mes de septiembre: $260 \mu \mathrm{g} / \mathrm{g}$.p.f. Con respecto a la categorización de los contenidos de almidón de las especies caducifolias, éstas presentaron categoría IV durante varios meses, en cambio, las especies siempreverdes presentaron una situación claramente diferente. La categoría IV sólo se presentó durante el mes de septiembre, previo a la floración de dichas especies. De los 24 individuos analizados de la especie N. obliqua, el 70\% aproximadamente presentaron categoría IV entre los meses enero a mayo, mientras que los meses restantes el contenido de almidón en el parénquima medular cayó dentro de la categoría III (cuadro 1). En forma similar, la especie $N$. alpina presentó categoría IV para la mayoría de los individuos analizados durante todos los meses de estudio (cuadro 2). 


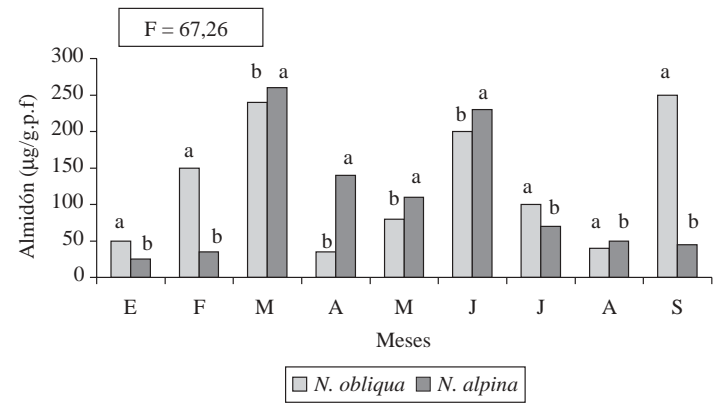

Figura 1. Contenido promedio de almidón en especies caducifolias. Letras distintas indican diferencia estadística. $(\mathrm{P}<0,05)$.

Average starch content in deciduous species. Statistic difference is indicated by different letters $(\mathrm{P}<0.05)$.

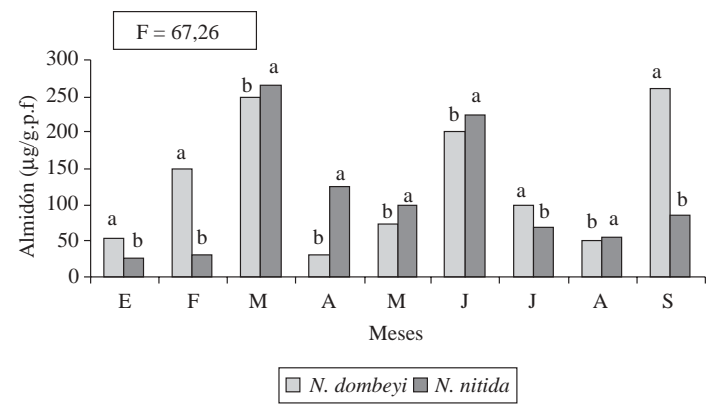

Figura 2. Contenido promedio de almidón en especies siempreverdes. Letras distintas indican diferencia estadística. $(\mathrm{P}<0,05)$

Average starch content in evergreen species. Statistic difference is indicated by different letters $(\mathrm{P}<0.05)$.

$N$. dombeyi se comportó de manera diferente a las dos especies anteriores, ya que durante la mayoría de los meses el contenido de almidón fluctuó entre las categorías I, II y III, presentando nula o casi nula cantidad de individuos en categoría IV. Además, cabe destacar que las cantidades de almidón presentes en el parénquima medular estuvieron por debajo de las encontradas en las especies caducifolias, valores que se encuentran, para la especie mencionada anteriormente, entre los $45 \mathrm{y}$ $50 \mu \mathrm{g} / \mathrm{g}$.p.f.

Similar comportamiento se observó en $N$. nitida, la cual no presentó acumulación específica durante un período determinado. También se aprecia que la acumulación de almidón se encontró entre las categorías II y III no presentando la categoría IV, excepto durante el mes de septiembre, período en el cual se produce las emergencia de hojas nuevas. En ambas especies, $N$. dombeyi y N. nitida, se apreció que la acumulación de granos de almidón no fue tan alta como en las especies caducifolias durante los primeros meses del año; sin embargo, en septiembre, el mes previo a la floración, el $100 \%$ de los individuos está en categoría IV, además se puede seguir en forma vertical la trayectoria de un individuo en los meses previos a la floración (cuadro 3 y 4).

En árboles caducifolios (N. obliqua y N. alpina) el incremento en la cantidad de granos de almidón se presentó en los primeros meses del año. En cambio, las especies siempreverdes ( $N$. dombeyi $y$ $N$. nitida) en los primeros meses del año se mantuvieron en categorías bajas, es decir, I y II.

El análisis de varianza determinó que la concentración de almidón presentó diferencias estadísticamente significativas entre las cuatro especies analizadas $(\mathrm{p}<0,05)$ y diferencias altamente significativas entre los meses de estudio ( $p<0,01)$. Mediante la prueba de Tukey $(95 \%)$ se determinó que las diferencias se presentaron entre las especies siempreverdes y las caducifolias, es decir, los valores de concentración de almidón fueron distintos para N. obliqua, $N$. alpina y $N$. dombeyi, $N$. nitida. De la misma manera se determinó que las concentraciones de almidón presentaron diferencias estadísticas entre los siguientes meses de estudio: enero, marzo, abril y junio, para las cuatro especies mencionadas.

A su vez, la interacción estadística entre las especies y los meses de estudio fue altamente significativa ( $p<0,01)$, lo que indica que las especies caducifolias poseen una tendencia a presentar las categorías más altas (III y IV) a lo largo de los meses de estudio, lo que concuerda con los resultados señalados anteriormente. Contrariamente a lo anterior ocurre con las especies siempreverdes, presentando las categorías más bajas (I y II) durante los primeros meses de año.

La clasificación visual de los individuos estudiados, en base a la acumulación de granos de almidón en el tejido medular, entre las especies caducifolias y siempreverdes mostró gran variabilidad de respuestas en igualdad de condiciones climáticas y edáficas. Las especies $N$. obliqua y $N$. alpina entre los meses de enero a mayo se mantuvieron mayoritariamente en categoría IV, para luego descender entre los meses de junio a agosto, previos a la floración. Por el contrario, las especies $N$. dombeyi y $N$. nitida, entre los meses de 
BOSQUE 24(3): 85-95, 2003

Cinética mensual de parámetros químicos en la fase de prefloración en especies del género Nothofagus

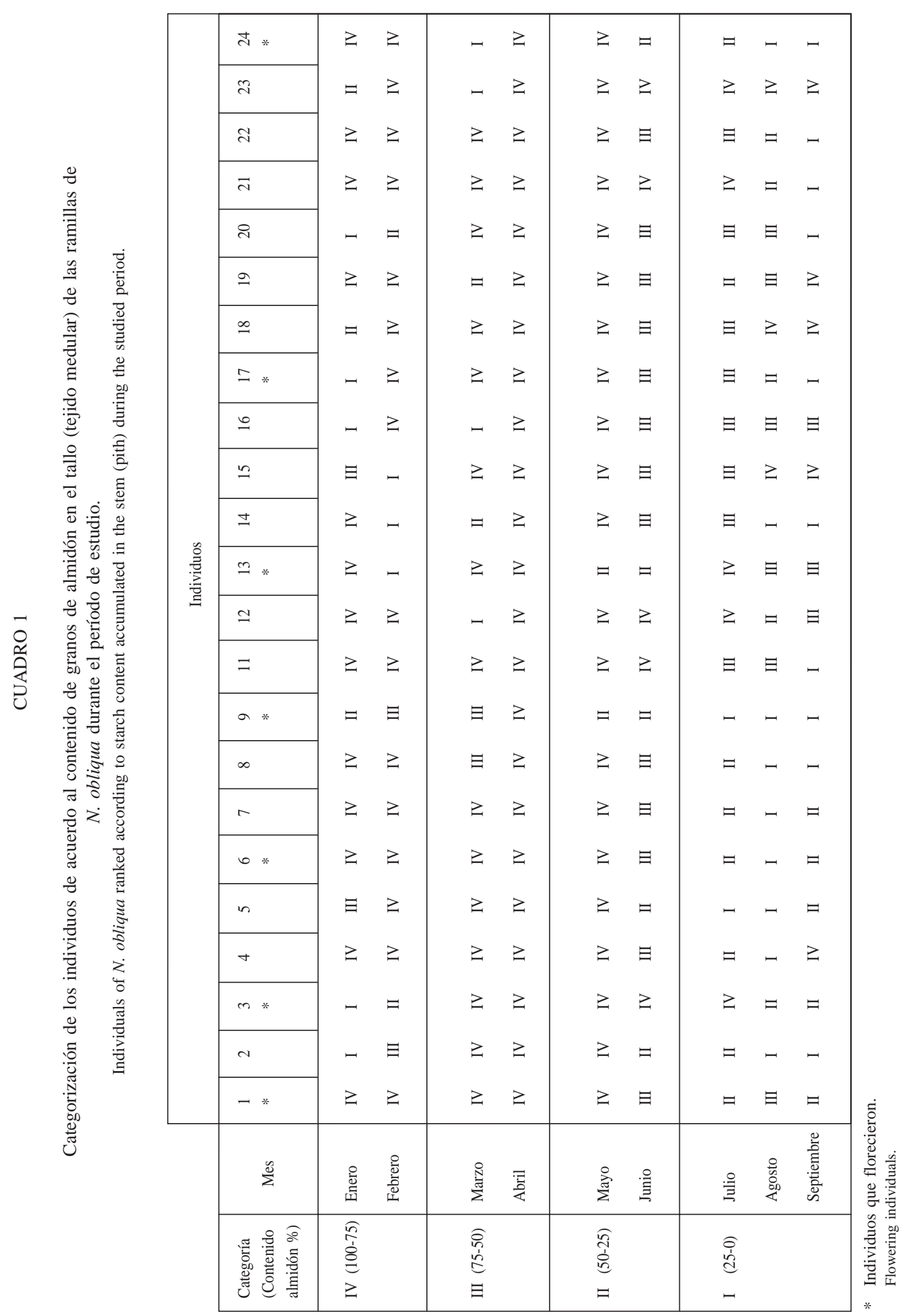


BOSQUE 24(3): 85-95, 2003

Cinética mensual de parámetros químicos en la fase de prefloración en especies del género Nothofagus

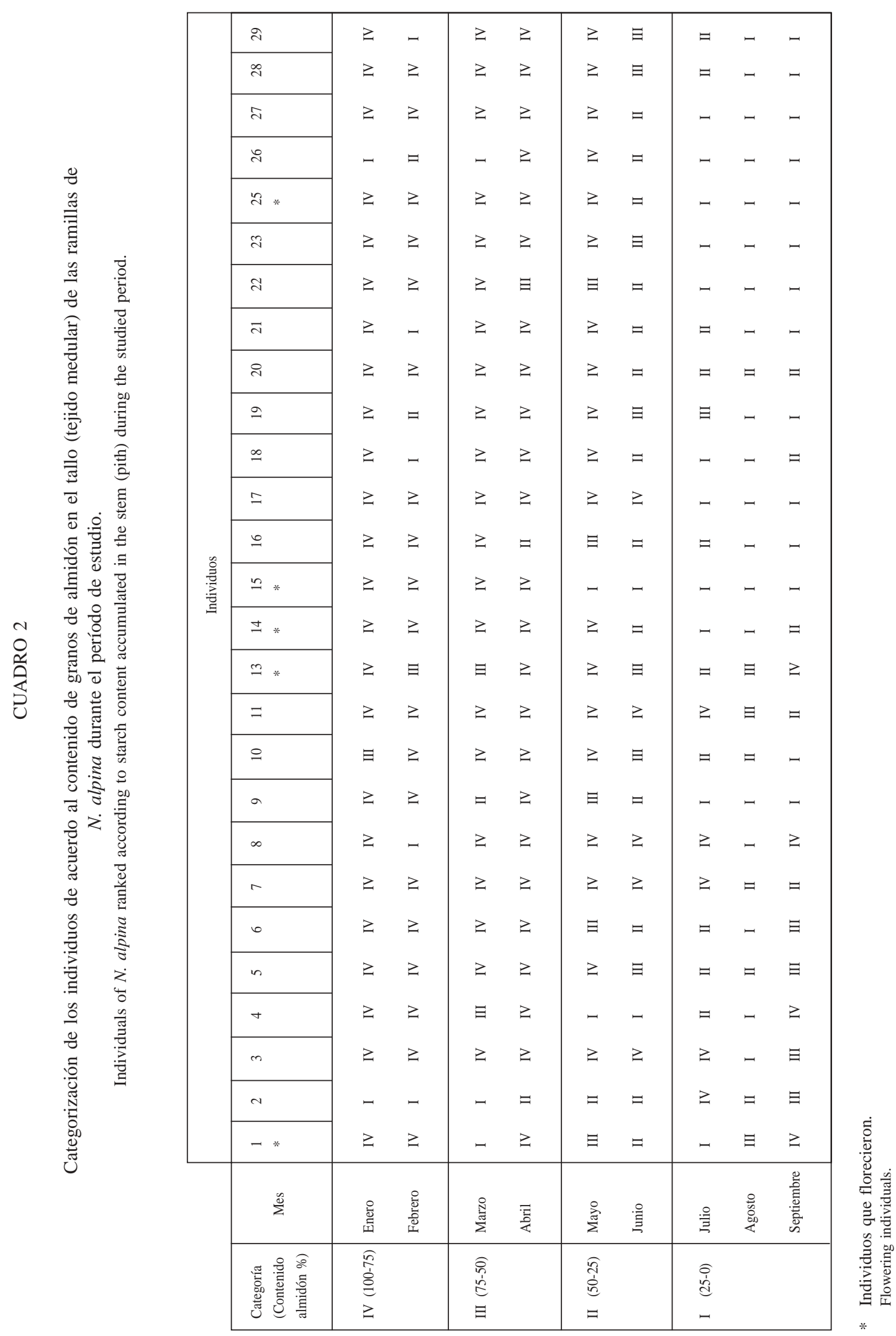




\section{CUADRO 3}

Categorización de los individuos de acuerdo al contenido de granos de almidón en el tallo (tejido medular) de las ramillas de $N$. dombeyi durante el período de estudio.

Individuals of $N$. dombeyi ranked according to starch content accumulated in the stem (pith) during the studied period.

\begin{tabular}{|c|c|c|c|c|c|c|c|c|c|c|c|}
\hline \multirow[b]{2}{*}{$\begin{array}{l}\text { Categoría } \\
\text { (Contenido } \\
\text { almidón \%) }\end{array}$} & \multirow[b]{2}{*}{ Mes } & \multicolumn{10}{|c|}{ Individuos } \\
\hline & & $\begin{array}{l}1 \\
*\end{array}$ & $\begin{array}{l}2 \\
*\end{array}$ & $\begin{array}{l}3 \\
*\end{array}$ & $\begin{array}{l}4 \\
*\end{array}$ & $\begin{array}{l}5 \\
*\end{array}$ & $\begin{array}{l}6 \\
*\end{array}$ & $\begin{array}{l}7 \\
*\end{array}$ & $\begin{array}{l}8 \\
*\end{array}$ & $\begin{array}{l}9 \\
*\end{array}$ & $\begin{array}{l}10 \\
*\end{array}$ \\
\hline IV (100-75) & $\begin{array}{l}\text { Enero } \\
\text { Febrero }\end{array}$ & $\begin{array}{l}\text { I } \\
\text { I }\end{array}$ & $\begin{array}{l}\text { II } \\
\text { I }\end{array}$ & $\begin{array}{l}\text { I } \\
\text { I }\end{array}$ & $\begin{array}{l}\text { II } \\
\text { I }\end{array}$ & $\begin{array}{l}\text { II } \\
\text { I }\end{array}$ & $\begin{array}{l}\text { II } \\
\text { I }\end{array}$ & $\begin{array}{l}\text { II } \\
\text { I }\end{array}$ & $\begin{array}{l}\text { II } \\
\text { I }\end{array}$ & $\begin{array}{l}\text { I } \\
\text { I }\end{array}$ & $\begin{array}{l}\text { I } \\
\text { I }\end{array}$ \\
\hline III $\quad(75-50)$ & $\begin{array}{l}\text { Marzo } \\
\text { Abril }\end{array}$ & $\begin{array}{l}\text { II } \\
\text { I }\end{array}$ & $\begin{array}{l}\text { I } \\
\text { I }\end{array}$ & $\begin{array}{l}\text { I } \\
\text { I }\end{array}$ & $\begin{array}{l}\text { III } \\
\text { I }\end{array}$ & $\begin{array}{l}\text { I } \\
\text { II }\end{array}$ & $\begin{array}{l}\text { II } \\
\text { II }\end{array}$ & $\begin{array}{l}\text { II } \\
\text { I }\end{array}$ & $\begin{array}{l}\text { I } \\
\text { II }\end{array}$ & $\begin{array}{l}\text { I } \\
\text { II }\end{array}$ & $\begin{array}{l}\text { I } \\
\text { I }\end{array}$ \\
\hline II $\quad(50-25)$ & $\begin{array}{l}\text { Mayo } \\
\text { Junio }\end{array}$ & $\begin{array}{l}\text { I } \\
\text { II }\end{array}$ & $\begin{array}{l}\text { I } \\
\text { II }\end{array}$ & $\begin{array}{l}\text { I } \\
\text { I }\end{array}$ & $\begin{array}{l}\text { I } \\
\text { I }\end{array}$ & $\begin{array}{l}\text { II } \\
\text { I }\end{array}$ & $\begin{array}{l}\text { II } \\
\text { I }\end{array}$ & $\begin{array}{l}\text { I } \\
\text { I }\end{array}$ & $\begin{array}{l}\text { II } \\
\text { II }\end{array}$ & $\begin{array}{l}\text { II } \\
\text { II }\end{array}$ & $\begin{array}{l}\text { I } \\
\text { I }\end{array}$ \\
\hline I $\quad(25-0)$ & $\begin{array}{l}\text { Julio } \\
\text { Agosto } \\
\text { Septiembre }\end{array}$ & $\begin{array}{l}\text { I } \\
\text { II } \\
\text { IV }\end{array}$ & $\begin{array}{l}\text { II } \\
\text { II } \\
\text { IV }\end{array}$ & $\begin{array}{l}\text { I } \\
\text { II } \\
\text { IV }\end{array}$ & $\begin{array}{l}\text { I } \\
\text { III } \\
\text { IV }\end{array}$ & $\begin{array}{l}\text { II } \\
\text { II } \\
\text { IV }\end{array}$ & $\begin{array}{l}\text { III } \\
\text { II } \\
\text { IV }\end{array}$ & $\begin{array}{l}\text { III } \\
\text { II } \\
\text { IV }\end{array}$ & $\begin{array}{l}\text { II } \\
\text { II } \\
\text { IV }\end{array}$ & $\begin{array}{l}\text { I } \\
\text { II } \\
\text { IV }\end{array}$ & $\begin{array}{l}\text { I } \\
\text { I } \\
\text { IV }\end{array}$ \\
\hline
\end{tabular}

* Individuos que florecieron.

Flowering individuals.

enero a junio se mantuvieron casi siempre entre las categorías I y II, comenzando a descender desde julio hasta septiembre. En este último mes, el $100 \%$ de los individuos de N. dombeyi y N. nitida alcanzaron categoría IV. Cabe destacar que las especies siempreverdes comienzan el período de floración más tarde que las especies caducifolias analizadas (Cárdenas 1994, Rosas 1994, Paredes 1995). Ellas comienzan a desarrollar estructuras vegetativas y reproductivas a contar de la segunda semana de octubre, lo que indicaría que a contar de este período habría consumo de sustancias energéticas en procesos de crecimiento y desarrollo, por ende habría disminución de estos compuestos.

En los individuos de las especies caducifolias analizadas que iban a florecer hubo demora en el desarrollo de las hojas, en relación a los que no florecieron. En estos últimos las hojas brotan antes y son más grandes y de un color verde intenso, lo que concuerda con las observaciones efectuadas principalmente en N. obliqua por Cárdenas (1994).
Esto indicaría que los individuos que van a florecer invierten una gran cantidad de energía para desarrollar estructuras vegetativas (ramillas) y estructuras reproductivas (flores) simultáneamente, a diferencia de otras especies en las que se detiene totalmente el crecimiento vegetativo para desarrollar las estructuras reproductivas (Bawa 1974). Esta inversión de energía, en los individuos que van a florecer, debería manifestarse en un aumento en la acumulación de granos de almidón en el tejido medular en los meses previos a la floración. Además, los individuos que presentaron categoría IV no siempre tuvieron concentraciones mayores de sustancias energéticas que las presentadas en las categorías I, II y III.

Carbohidratos solubles totales: El contenido de carbohidratos solubles totales, tanto en las especies caducifolias como en las siempreverdes, se mantuvo dentro de los 100 a $120 \mu \mathrm{g} / g . p . f$. durante los nueve meses de evaluación (figuras 3 y 4). El 
BOSQUE 24(3): 85-95, 2003

Cinética mensual de parámetros químicos en la fase de prefloración en especies del género Nothofagus

análisis de varianza determinó que el contenido de carbohidratos presentó diferencias significativas entre las cuatro especies evaluadas $(\mathrm{p}<0,05)$ y diferencias altamente significativas entre los meses de estudio ( $\mathrm{p}<0,01)$. Mediante la prueba de Tukey $(95 \%)$ se determinó que las diferencias se presentaron entre las especies siempreverdes y las caducifolias, es decir, los valores de concentración de carbohidratos fueron distintos para $N$. obliqua, $N$. alpina y N. dombeyi, N. nitida. De igual forma se determinó que las concentraciones de carbohidratos solubles totales presentaron diferencias entre los siguientes meses en estudio: abril, julio y septiembre.

\section{CUADRO 4}

Categorización de los individuos de acuerdo al contenido de granos de almidón en el tallo (tejido medular) de las ramillas de $N$. nitida durante el período de estudio.

Individuals of $N$. nitida ranked according to starch content accumulated in the stem (pith) during the studied period.

\begin{tabular}{|c|c|c|c|c|c|c|c|c|c|}
\hline \multirow[b]{2}{*}{$\begin{array}{l}\text { Categoría } \\
\text { (Contenido } \\
\text { almidón \%) }\end{array}$} & \multirow[b]{2}{*}{ Mes } & \multicolumn{8}{|c|}{ Individuos } \\
\hline & & $\begin{array}{l}1 \\
*\end{array}$ & $\begin{array}{l}2 \\
*\end{array}$ & 3 & 4 & 5 & $\begin{array}{l}6 \\
*\end{array}$ & 7 & $\begin{array}{l}8 \\
*\end{array}$ \\
\hline IV (100-75) & $\begin{array}{l}\text { Enero } \\
\text { Febrero }\end{array}$ & $\begin{array}{l}\text { I } \\
\text { I }\end{array}$ & $\begin{array}{l}\text { II } \\
\text { II }\end{array}$ & $\begin{array}{l}\text { I } \\
\text { II }\end{array}$ & $\begin{array}{l}\text { II } \\
\text { II }\end{array}$ & $\begin{array}{l}\text { I } \\
\text { I }\end{array}$ & $\begin{array}{l}\text { I } \\
\text { I }\end{array}$ & $\begin{array}{l}\text { I } \\
\text { I }\end{array}$ & $\begin{array}{l}\text { II } \\
\text { I }\end{array}$ \\
\hline III $\quad(75-50)$ & $\begin{array}{l}\text { Marzo } \\
\text { Abril }\end{array}$ & $\begin{array}{l}\text { I } \\
\text { IV }\end{array}$ & $\begin{array}{l}\text { I } \\
\text { III }\end{array}$ & $\begin{array}{l}\text { I } \\
\text { II }\end{array}$ & II & $\begin{array}{l}\text { I } \\
\text { II }\end{array}$ & $\begin{array}{l}\text { II } \\
\text { I }\end{array}$ & $\begin{array}{l}\text { I } \\
\text { II }\end{array}$ & $\begin{array}{l}\text { I } \\
\text { I }\end{array}$ \\
\hline II $\quad(50-25)$ & $\begin{array}{l}\text { Mayo } \\
\text { Junio }\end{array}$ & $\begin{array}{l}\text { II } \\
\text { II }\end{array}$ & $\begin{array}{l}\text { III } \\
\text { II }\end{array}$ & $\begin{array}{l}\text { III } \\
\text { I }\end{array}$ & & $\begin{array}{l}\text { III } \\
\text { III }\end{array}$ & $\begin{array}{l}\text { I } \\
\text { II }\end{array}$ & $\begin{array}{l}\text { II } \\
\text { II }\end{array}$ & $\begin{array}{l}\text { II } \\
\text { I }\end{array}$ \\
\hline I $\quad(25-0)$ & $\begin{array}{l}\text { Julio } \\
\text { Agosto } \\
\text { Septiembre }\end{array}$ & $\begin{array}{l}\text { I } \\
\text { I } \\
\text { IV }\end{array}$ & $\begin{array}{l}\text { III } \\
\text { II } \\
\text { IV }\end{array}$ & $\begin{array}{l}\text { II } \\
\text { I } \\
\text { IV }\end{array}$ & & $\begin{array}{l}\text { IV } \\
\text { I } \\
\text { IV }\end{array}$ & $\begin{array}{l}\text { I } \\
\text { I } \\
\text { IV }\end{array}$ & $\begin{array}{l}\text { II } \\
\text { I } \\
\text { IV }\end{array}$ & $\begin{array}{l}\text { I } \\
\text { II } \\
\text { IV }\end{array}$ \\
\hline
\end{tabular}

* Individuos que florecieron

Flowering individuals.

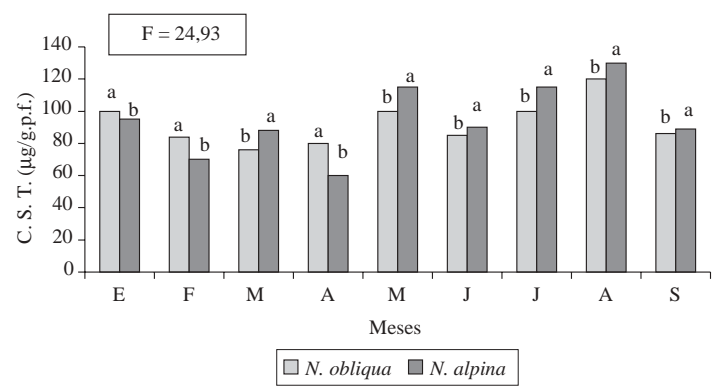

Figura 3. Contenido promedio de carbohidratos solubles totales en especies caducifolias. Letras distintas indican diferencia estadística. ( $\mathrm{P}<0,05)$.

Average of total soluble carbohydrates in deciduous species. Statistic difference is indicated by different letters $(\mathrm{P}<0.05)$.

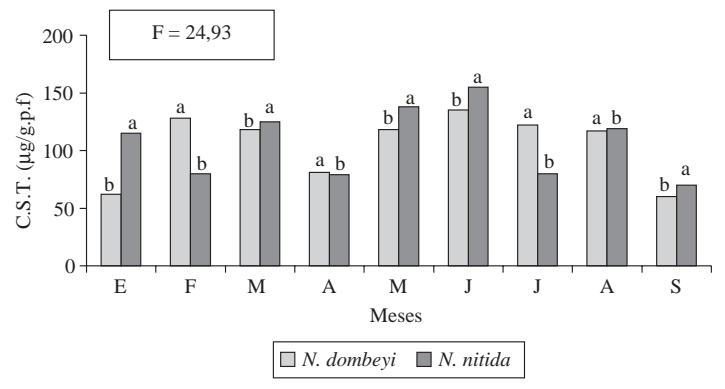

Figura 4. Contenido promedio de carbohidratos solubles totales en especies siempreverdes. Letras distintas indican diferencia estadística. $(\mathrm{P}<0,05)$.

Average of total soluble carbohydrates in evergreen species. Statistic difference is indicated by different letters $(\mathrm{P}<0.05)$. 
A su vez, la interacción estadística entre las especies y los meses de estudio fue altamente significativa, lo que implica que las especies caducifolias poseen una tendencia a presentar las categorías más altas, es decir, III y IV, a lo largo de los meses de estudio, lo que concuerda con los resultados señalados anteriormente. Contrariamente a lo anterior ocurre en las especies siempreverdes presentando las categorías más bajas, es decir, I y II durante los meses de año.

El análisis de carbohidratos solubles totales y almidón se realizó en la misma muestra para obtener una idea clara sobre la relación que pudiese haber en estos compuestos, ya que es conocido que la síntesis de compuestos es, a menudo, dependiente de la síntesis del otro. Se ha visto que en plantas de arroz las concentraciones de azúcares solubles aumentan rápidamente desde la formación de yemas florales hasta una floración alta. En contraste, las concentraciones de almidón disminuyen rápidamente a niveles mínimos, lo que sugiere la hidrólisis de almidón a glucosa para ser utilizada en el crecimiento o desarrollo de flores (Kawasaki et al. 1996). Al comparar lo anterior con las especies caducifolias se observó que $N$. obliqua y $N$. alpina en el período previo a la floración presentaron concentraciones de carbohidratos mayores que las de almidón, pero esto no se mantuvo siempre, ya que hubo excepciones como las de categorías III y IV en $N$. obliqua y la categoría II en $N$. alpina.

La observación realizada en plantas de arroz, a pesar de ser diferentes formas de vida, coincide completamente con lo obtenido para las especies siempreverdes, las cuales a medida que se acercaba el período de floración aumentaron las concentraciones de carbohidratos solubles totales. Para dichas especies las concentraciones de almidón fueron bajas en comparación a las especies caducifolias ya que $N$. dombeyi presentó la concentración más alta en septiembre y $N$. nitida obtuvo la concentración más alta en junio.

Cabe destacar que las concentraciones de carbohidratos mostraron un leve aumento a contar del mes de junio. Los valores de dichas concentraciones fueron más altos en las especies caducifolias que en las siempreverdes. Este aumento podría deberse a las bajas temperaturas, ya que en el período de estudio se presentaron temperaturas bajo cero y precipitaciones nivales. Esto confirmaría las observaciones de que el almidón se hidroliza en carbohidratos por bajas temperaturas (Levit 1980). Por otra parte, el almidón se desdobla en azúcares simples, como un medio de protección contra las bajas temperaturas, ya que éstos actúan como sustancias osmorreguladoras frente a diferentes tipos de estrés (Alberdi et al. 1993). También se pudo observar que los individuos siempreverdes, a pesar de tener la posibilidad de fotosintetizar en los períodos favorables y transitorios de invierno, debido a que no pierden su follaje, no obtuvieron concentraciones mayores de carbohidratos que las especies caducifolias.

En estudios realizados en mandarinas se concluyó que la diferenciación de yemas florales no tiene correlación directa con el contenido de carbohidratos totales solubles (Yahata et al. 1996). Esta situación podría aplicarse en algunos casos para los individuos siempreverdes ya que las concentraciones de carbohidratos no presentaron rangos muy diferentes entre las diferentes categorías y, a pesar de ello, floreció el $50 \%$ de $N$. nitida y el $100 \%$ de N. dombeyi.

En las cuatro especies estudiadas se pudo observar un patrón distinto de acumulación de sustancias energéticas en relación a la floración. En las especies caducifolias los individuos que florecieron durante los primeros meses de estudio acumularon granos de almidón en sus ramillas, para luego en los meses previos a la floración disminuir en categoría. Sin embargo, se presentaron individuos que a pesar de tener este comportamiento no florecieron. Lo anterior podría deberse a que estas especies siguen el patrón de floración periódica del resto de los Nothofagus y habría que agregar que la floración es un carácter altamente heredable, de modo que es un elemento muy importante a considerar en cualquier ensayo en función de flores, frutos y semillas (Donoso 1993). Quizás las especies caducifolias que no florecieron a pesar de presentar igual comportamiento que los individuos que florecieron consumirían mayor cantidad de carbohidratos, además de necesitar un período específico para acumular reservas agotadas antes de volver a florecer (Donoso 1993).

Proteínas totales: Los análisis de proteínas totales mostraron que para las cuatro especies en estudio se presentó un leve aumento del contenido en el período de estudio, aumento que fue visible a contar del mes de junio (figuras 5 y 6). Estos resultados también mostraron que los valores más altos en proteínas totales fueron independientes de las categorías elaboradas a partir del contenido de almidón en el tejido medular. 


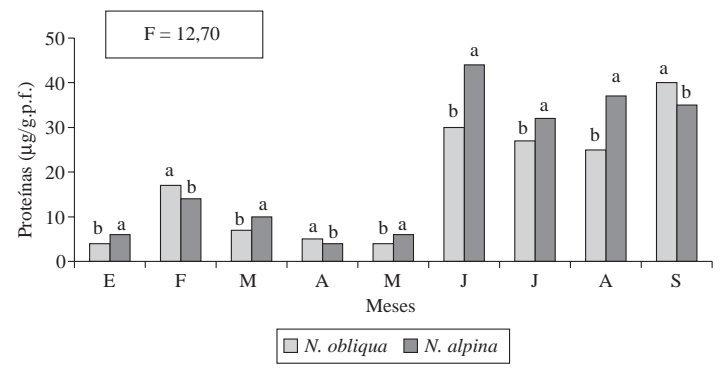

Figura 5. Contenido promedio de proteínas en especies caducifolias. Letras distintas indican diferencia estadística. $(\mathrm{P}<0,05)$.

Average protein content in deciduous species. Statistic difference is indicated by different letters $(\mathrm{P}<0.05)$.

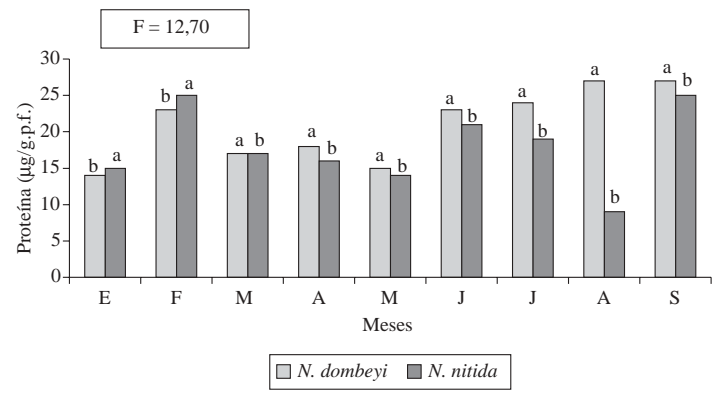

Figura 6. Contenido promedio de proteínas en especies siempreverdes. Letras distintas indican diferencia estadística. $(\mathrm{P}<0,05)$.

Average protein content in evergreen species. Statistic difference is indicated by different letters $(\mathrm{P}<0.05)$.

El valor más alto de contenido de proteínas para la especie $N$. obliqua fue de $46,4 \pm 0,7 \mu \mathrm{g} / \mathrm{g}$.p.f., valor que se presentó durante el mes de septiembre, clasificándose en categoría II. El menor valor de contenido de proteínas se obtuvo en el mes de enero y se clasificó en categoría I. Para la especie $N$. alpina el valor más alto se presentó entre los meses de junio y septiembre con un promedio de $45,6 \pm 0,9 \mu \mathrm{g} / \mathrm{g}$.p.f., siendo este valor clasificado en la categoría I. Cabe destacar que en el mes de abril la mayoría de los individuos se ubicaron en categoría IV. Sin embargo, los registros de proteínas mostraron los valores más bajos.

Los valores en proteínas de las diferentes categorías fueron más fluctuantes para $N$. nitida que para $N$. dombeyi, habiéndose obtenido los valores máximos $(25,8 \pm 1,7 \mu \mathrm{g} / \mathrm{g}$.p.f. $)$ en el mes de febrero y en categoría I. El análisis de varianza determinó que la concentración de proteínas presentó diferencias estadísticamente significativas entre las cuatro especies analizadas y entre los meses de estudio ( $\mathrm{p}<0,05)$. De igual forma se determinó que las concentraciones de proteínas presentaron diferencias entre los siguientes meses en estudio: enero, abril, mayo y julio.

A su vez, la interacción estadística entre las especies y los meses de estudio fue altamente significativas, lo que indica que las especies caducifolias poseen una tendencia a presentar las categorías más altas, es decir, III y IV, a lo largo de los meses de estudio, lo que concuerda con los resultados señalados anteriormente. Lo contrario a lo anterior ocurre en las especies siempreverdes, presentando las categorías más bajas, es decir, I y II durante los meses del año.

Con respecto a las proteínas totales, éstas presentaron un leve aumento desde enero a junio, mes en que el aumento se hace apreciable. Dicho aumento se registró en todas las categorías y para todas las especies, y podría asociarse a un medio de protección contra las bajas temperaturas, ya que en dicho mes comienza el invierno y con éste un descenso de las temperaturas. El aumento de proteínas, específicamente de proteína libre, también se reportó en hojas de $N$. dombeyi, donde se observó que a medida que se acercaba el período otoño-invierno aumentaba la concentración de prolina (Mesa et al. 1986). El aumento de proteínas solubles también fue observado en especies de Solanum (Barrientos et al. 1994) y en cultivos de Avena sativa aclimatada al frío (Alberdi et al. 1993). Dicha aclimatación podría asemejar las bajas temperaturas de las estaciones de otoño e invierno para las especies de Nothofagus. Esto último estaría de acuerdo con el hecho de que las plantas frente a situaciones de estrés, como por ejemplo la sequía fisiológica por bajas temperaturas, sintetizan proteínas (Larcher 1995). Otra observación que se destaca referente a las proteínas es el hecho de que las concentraciones más altas fueron independientes de las categorías elaboradas a partir del contenido de almidón en el tejido medular, lo que estaría indicando que no hay relación entre valores de proteínas y categorías según acumulación de granos de almidón.

Floración: Respecto de la floración se puede apreciar que los individuos caducifolios presentan un comportamiento similar con respecto a la acumulación de almidón a medida que pasa el tiempo (cuadros 1, 2, 3 y 4). Lo mismo ocurre para los individuos siempreverdes. Esto es, las especies $N$. obliqua y $N$. alpina acumulan almidón en los primeros meses del año, para luego, a contar del 
mes de junio, descender de categoría. Sin embargo, a pesar de que la gran parte de los individuos acumuló almidón, no todos presentaron floración.

El 36\% de los individuos analizados de la especie $N$. obliqua florecieron, y el $18,5 \%$ de los individuos de la especie $N$. alpina presentaron floración. En los individuos que no florecieron se observó que las hojas aparecieron antes que las hojas de aquellos individuos que sí florecieron y éstas fueron más grandes y de un color verde intenso.

Para los individuos siempreverdes se observó que en los primeros meses del año no acumularon almidón, ya que se encontraron en categorías bajas, para luego, a contar del mes de septiembre, se produce un aumento de categoría en la especie $N$. dombeyi, lo que significa que acumulan sustancias energéticas. El 100\% de los individuos de la especie N. dombeyi florecieron y sólo el $50 \%$ de los individuos lo hizo en la especie $N$. nitida.

\section{CONCLUSIONES}

Las cuatro fagáceas estudiadas no mostraron un patrón de floración similar a pesar de pertenecer al mismo género.

No hay una clara relación entre acumulación de reservas energéticas y la floración, probablemente es necesario seguir un registro durante varios años o varios períodos de floración.

La acumulación de reservas es independiente de cada planta, aun bajo condiciones similares de suelo y microclima.

Los Nothofagus siempreverdes presentaron un patrón de acumulación de reservas absolutamente diferente en relación con los caducifolios.

La floración de las especies simpreverdes es más dependiente del patrón de reserva en los meses previos a la floración.

\section{AGRADECIMIENTOS}

Los autores desean expresar su agradecimiento por su valiosa cooperación a la Dra. Miren Alberdi L., a la profesora Magdalena Romero A., al señor Julio Fernández.

\section{BIBLIOGRAFIA}

ALBERDI, M., L. CORCUERA, C. MALDONADO, M. BARRIENTOS, J. FERNANDEZ, O. HENRIQUEZ. 1993. "Cold acclimation in cultivars of Avena sativa", Phytochemistry 33: 57-60.

BARRIENTOS, M., MOL, E., PERUZZO, G., CONTRERAS, A. \& M. ALBERDI. 1994. "Responses to cold of Chilean wild Solanunm species", Environmental and Experimental Botany 34 (1): 47-54.

BAWA, K. S. 1974. "Breeding systems of tree species of lowland tropical community", Evolution 28: 85-92.

BAWA, K. S. 1983. "Patterns of flowering in tropical plants". Handbook of Experimental Pollination Biology. C. E. Jones \& R. J. Little (eds.), Van Nostrand Reinhold, New York. 394-410 p.

BORCHET, R. 1983. Phenology and control flowering in tropical trees. Biotropica 15: 81-89

BRADFORD, M. M. 1976. "A rapid and sensitive method for the quantification of microgram quantities of protein using the principle of protein dye binding", And. Biochem 72: 248-254.

CARDENAS, E. DE L. 1994. Flujo de polen, reproducción y fecundidad en Nothofagus obliqua (Mirb.) Oerst. Tesis Pedagogía de Biología, Química y Cs. Naturales. Universidad Austral de Chile. 82 p.

GAUTIER-HION, A. 1991. "Interactions among fruit and vertebrate fruit eaters in an African tropical rain forest". In: K. S. Bawa y M. Handley (eds.) Reproductive Ecology of tropical plants. Man and the Biosphere Series. The Parthenon, London. 219-230 p.

DONOSO, C. 1987. "Variación natural en especies de Nothofagus en Chile". Bosque: 8 (2): 85-97.

DONOSO, C. 1993. Bosques templados de Chile y Argentina. Variación, Estructura y Dinámica. Editorial Universitaria. $477 \mathrm{p}$.

DUBOIS, M. K.A. GILLES, J.K. HAMILTON, REBES \& P. A. SMITH. 1959. "Complex carbohydrates". In: Methods in Enzimology (L. NEUFELD 1996) 8: 93-95.

KAWASAKI, T., K. MIZUNO, H. HIMADA, H. SATHO, N. KISHIMOTO, S. OKUMURA, N. ICHIKAWA \& T. BABA. 1996. "Coordinated regulation of the genes participating in starch biosynthesis by the rice Floury-2-locus", Plant Physiology 110: 89-96.

LARCHER, W. 1995. Physiological Plant Ecology. T ${ }^{\text {rd }}$ edition. Springer Verlag, New York. $502 \mathrm{p}$.

LEVIT, J. 1980. "Chilling, freezing and high temperative stress". In: TT. Kozlowski (Ed.). Response of Plants to Environmental Stresses. Academic Press, New York.

MESA, L., P. GUARDA, D. RIOS \& M. ALBERDI. 1986. "Changes in free aminoacid content and frost resistance in Nothofagus dombeyi leaves", Phytochemistry 258: 1843-1846.

PAREDES, M. A. 1995. Polinización y factores que afectan el desarrollo de semillas viables en la especie Nothofagus dombeyi (Mirb.) Oerst. FAGACEAE. Tesis Pedagogía de Biología, Química y Cs. Naturales. Universidad Austral de Chile. 87 p.

ROSAS, M. T. 1994. Fenología, reproducción y viabilidad en la especie Nothofagus nitida (Phil.) Krasser. Tesis Pedagogía de Biología, Química y Cs. Naturales. Universidad Austral de Biología, Q
de Chile. $67 \mathrm{p}$.

WARDLE, J. A. 1984. The New Zealand beeches, N. Zealand Forest Service, Christchurch, New Zealand.

YAHATA., D., OBEA \& M.N. KUWAHARA. 1996. "Alpha amylase activity, indolacetacid and gibberellin-like substances in the summer Shoots of wase satsuma mandarin trees grown indoors during flower bud differentiation". Journal of the Japanese Society for Horticultural Science 64 3: 527-533. 